\title{
IMPACT OF BUILDING REGULATIONS ON THE URBAN FABRIC OF THE CITY: CASE STUDY OF ALEXANDRIA, EGYPT
}

\author{
NADIA SAMIR ${ }^{1}$, RAMADAN ABD EL MAKSOUD ${ }^{2} \&$ IBRAHIM MAAROF $^{2}$ \\ ${ }^{1}$ Pharos University, Egypt \\ ${ }^{2}$ Alexandria University, Egypt
}

\begin{abstract}
The physical form and pattern of built environments in a city are the outcome of prevalent planning and design standards and building regulations. Many issues of built environments in urban settlements are the consequence of prevailing building regulations in that settlement. These building regulations have been copied and adopted from one place to another across the country, having an enormous impact on the functioning, character, quality, safety and image of a city. The role of building codes in the formation of the urban fabric of cities and the impact on architecture and planning identity are addressing different models of the types of laws and their impact on cities. General frameworks and guidelines for linking laws and building regulations were developed with the formation of the urban fabric and the mechanisms of changing these regulations temporally and spatially in order to preserve the identity and the positive intervention in the formation of the urban fabric of the city. In accordance with the Geo-environmental, developmental and technological context, new building frameworks and guidelines that are applicable at the area/zone level in Alexandria, Egypt were formulated. Various crucial factors/criteria which are essential for appropriate development in towns were determined and can therefore become the basis for new building regulations.
\end{abstract}

Keywords: building regulations, urban fabric, built environment, building codes, building height.

\section{INTRODUCTION}

With the beginning of the organization of the urban movement in Egypt, the authorities resorted to a set of legislation, mostly derived from the European systems, which produced a semi-European urban fabric that deprived the city of many of the characteristics that should stem from the customs, traditions and the nature of the atmosphere in the country [1].

The laws changed from Khedive to Sultan and president, passing by British occupation, and Ottoman rule until the first law on the organization of buildings No. 51 of 1940 was issued, the first law dealing with construction work, and was linked to the regulation issued in December 1889, where the conditions contained in this regulation relate only to public roads and regulatory lines. The law dealt with the organization of the building itself and its connection to the surrounding urban environment. It stipulated that no building should be erected or modified except with respect to certain rules, including the maximum height of the building and its relation to the road width, the minimum height of each floor, the interior ventilation and lighting of rooms and facilities. In addition, it addressed some of the security factors related to fires and the means of extinguishing them. In this law, the legislator intervened for the first time to limit the freedom of individuals to use the right of ownership to get light and air to the buildings with the aim of establishing a healthy home, as well as the adequate access of light and air to streets and public paths for the public good. Besides this law, the law 52 of 1940 was issued to regulate the division of land as a planning process prior to construction [2], [3].

Law 656 of 1954 was issued to replace both the High Order of 1889 and the Law of Organization 51 of 1940, combining the two laws into one law of the same subjects. This law remained in force for approximately eight years until it was subsequently developed several 
times. Such development was done either by adding requirements that dealt with more details, or by modifying earlier requirements for improvement.

In 1962, Law 45 was issued, not much different from the previous one, dealing with the width of roads and building heights, as well as new conditions related to the openings of buildings for lighting, ventilation and the stairs to ensure the quality of the construction process.

In 1976, the Building Regulation Law 106 was issued in addition to a regulation issued by the Ministry of Housing No. 237 of 1977 that includes many details of the construction work. It was submitted to dozens of amendments after it was issued, this law works in addition to the Land Division Law 52 of 1940, Planning and Building Law 3 of 1982.

The building codes related to the height item and building requirements laws passed through three phases that influenced the urban composition until the present time. These phases are summarized in Fig. 1.

\subsection{First phase (Law 51 of 1940)}

The height of the building shall be equal to one and a half times the width of road with a maximum height of $35 \mathrm{~m}$. If the building is located on roads that differ in width, the height in all the façades may reach the maximum height of the wider road [4].

\subsection{Second phase (Law 656 of 1954, Law 45 of 1962, Law 106 of 1976 and Amended Law 106 of 1976)}

The height of the building shall be equal to one and a half times the width of road with a maximum height of $36 \mathrm{~m}$. If the building is located at the intersection of two roads whose width is different, the height of the façade overlooking the smaller road shall rise to the maximum allowable height for the wider road, this height Within a maximum depth in the smaller road equal to the width of the wider road and it shall not exceed $25 \mathrm{~m} \mathrm{[5]-[8].}$

\subsection{Third phase (Law 119 of 2008 (The Unified Building Law))}

The laws of urban planning and the organization of buildings were integrated into one law, which was promulgated by the Unified Building Law. Several strategic city plans were adopted Based on Article 29, the section on building heights became part of the structural requirements attached to the city's strategic plan. These conditions are adopted with the adoption of the strategic plan for each city [9].

The legal rules for building height through the structural requirements of the strategic plan of Alexandria will be reviewed as the chosen model for the field study to apply the legal rule which is the subject of the research as follows [10]. The height of the building shall be equal to one and a half times the width of road with a maximum height of $42 \mathrm{~m}$, and the legal rule for the height of the building on two different roads stipulates that: "If the building is located at the intersection of two opposite sides with different width, the width of the building height is equal to one and a half times the width of wider road with a maximum height of 36 meters" (without any restrictions). The height limit on the smaller road has been eliminated, which is exactly the same as it was in the first phase of the 1940s. The building became full height on the wider road and along the smaller road. 

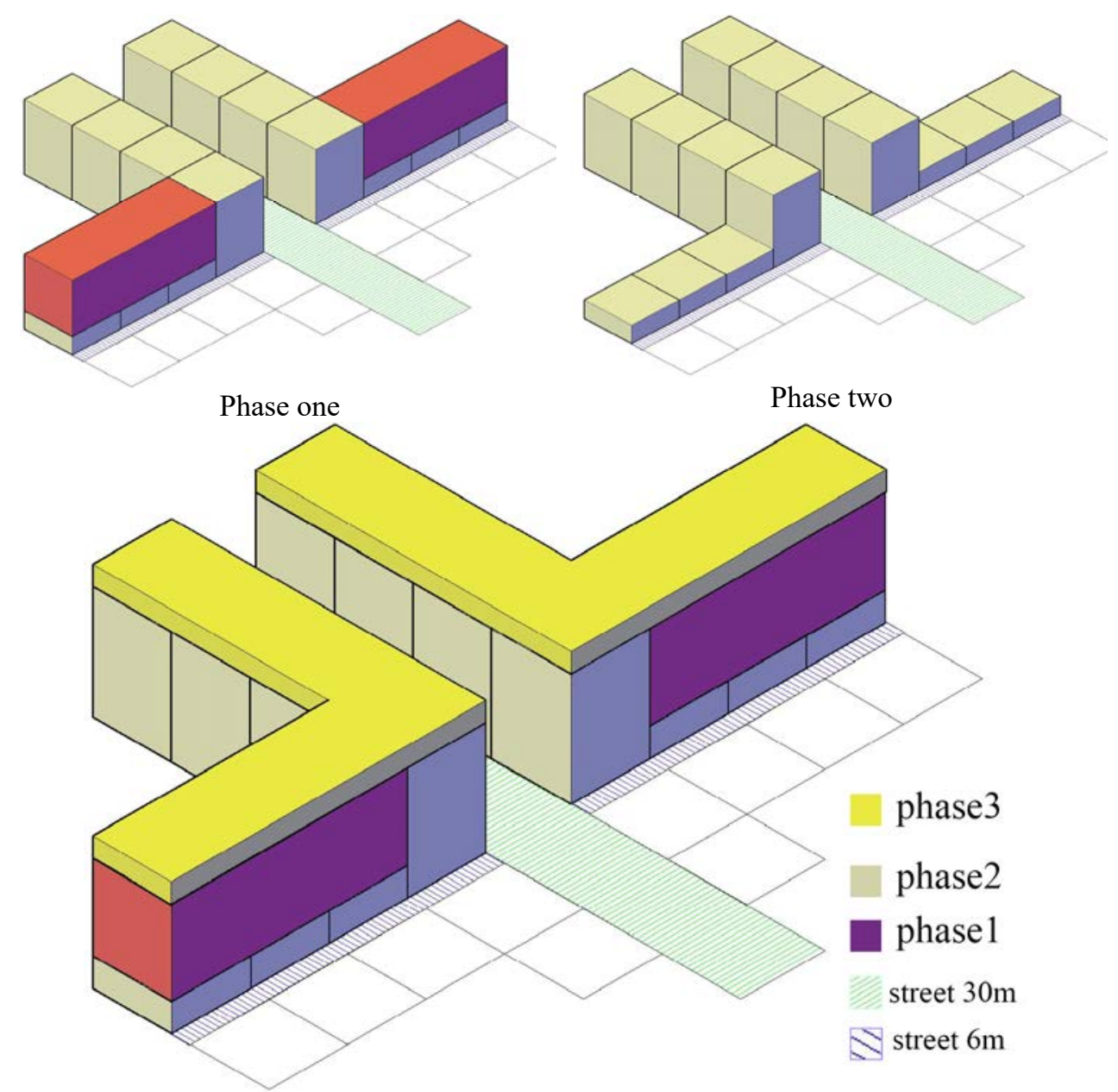

Phase three (current law)

Figure 1: The three stages passed by the Egyptian construction laws.

The lighting and ventilation parameters in the current law stipulate that:

- The internal area of the room shall not be less than $7.5 \mathrm{~m}$, where the minimum width is $2.5 \mathrm{~m}$, as the internal height of the room, shall not be less than $2.7 \mathrm{~m}$. the room shall have an opening or several openings overlooking the road, which shall not be less than $8 \%$ of the room area and at a minimum of $1 \mathrm{~m}^{2}, 90 \mathrm{~cm}$ up from the room floor.

- The height between the bottom part of the balcony or the residential projection shall not be less than $4 \mathrm{~m}$ from the street surface, where the maximum protrusion of balconies shall not exceed $10 \%$ and the projections shall not exceed $5 \%$ of the width of the road. In both cases the protrusions shall not exceed $1.25 \mathrm{~m}$ [11].

- The lowest length in the courtyard is $0.25 \%$ from total height of building, at least $3 \mathrm{~m}$. 


\section{RESEARCH LOCATION}

A residential area in Egypt is selected in Alexandria, the extension of the university bridge in a selective manner (Fig. 2), where different models of street widths are available $(6,8,12$, $20,24 \mathrm{~m}$ ) to apply the current legal rule, as the height is related to the width of the road.

A field survey is carried out for the height of the legal buildings (without addressing the violations) and the current street width. Fig. 3 shows the heights of the buildings in the area and the shape of the urban fabric, where structural heights are determined by the width of the streets overlooking them.

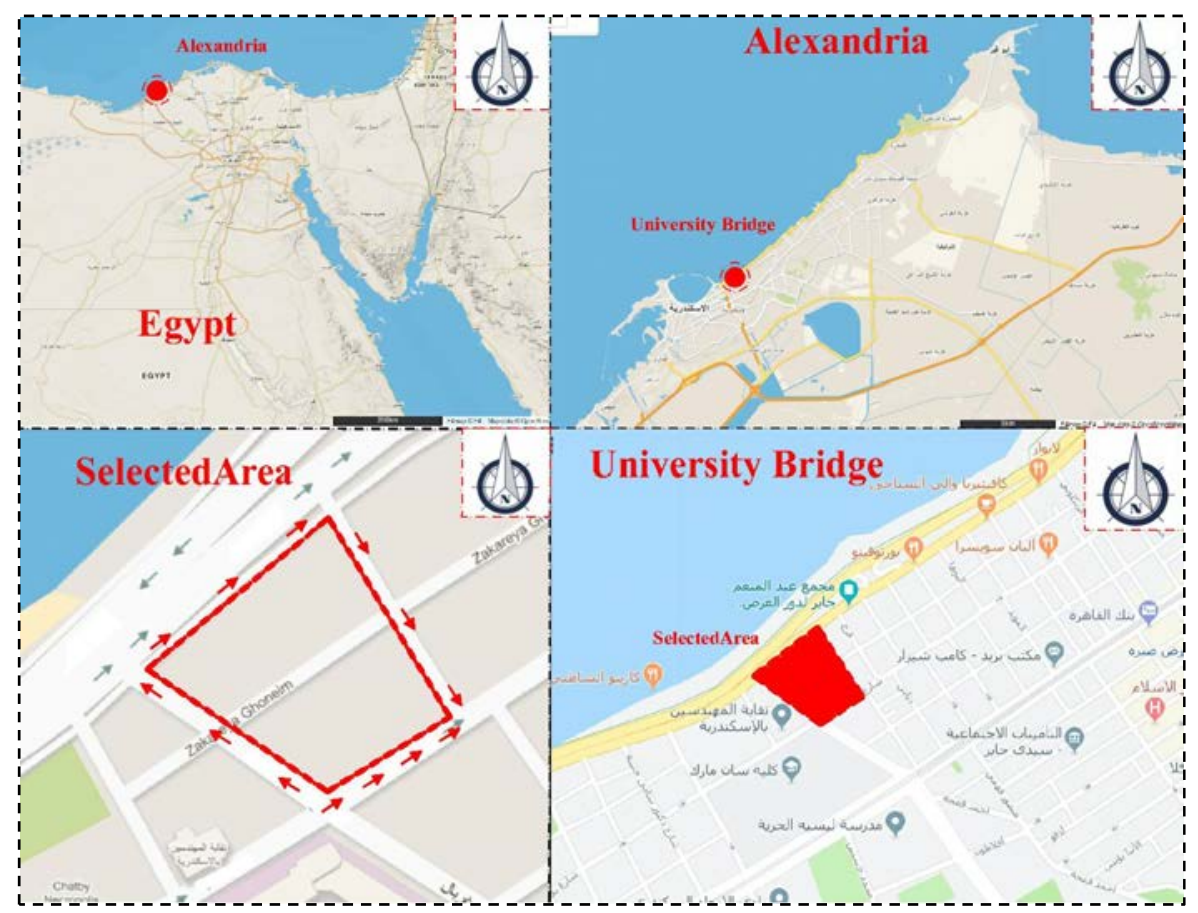

Figure 2: Study location. (Source: https://demo.f4map.com.)
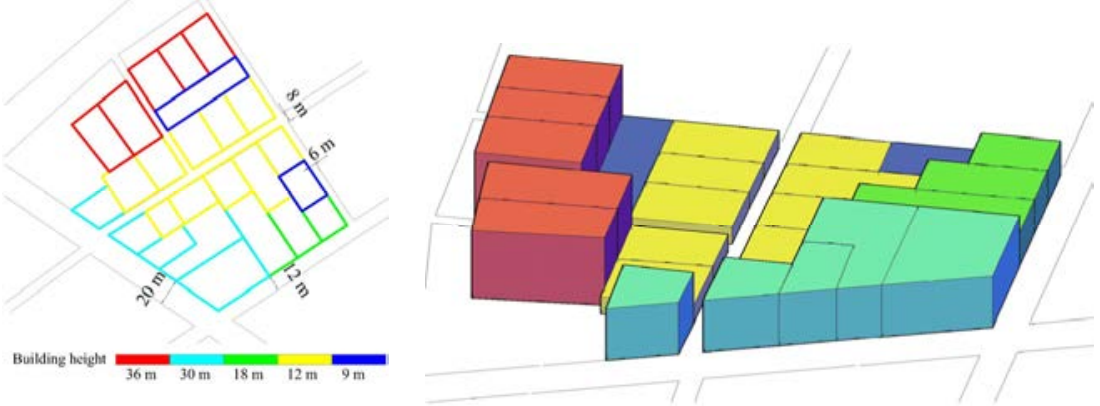

Figure 3: The height of existing buildings in the selected area and the width of the streets. 
Based on the field survey of the height of the buildings and street width in the area, the buildings overlooking Port Said Street with width of $12 \mathrm{~m}$ will be of a maximum height of $18 \mathrm{~m}$. Similarly, the buildings overlooking Mohammed Shafiq street with width of $20 \mathrm{~m}$ have a maximum height of $30 \mathrm{~m}$ and the buildings overlooking the side streets with $6 \mathrm{~m}$ and $8 \mathrm{~m}$ width shall have a maximum height of $9 \mathrm{~m}$ and $12 \mathrm{~m}$ respectively. As for the sea road, it takes the maximum height of $42 \mathrm{~m}$ as shown in Fig. 4.

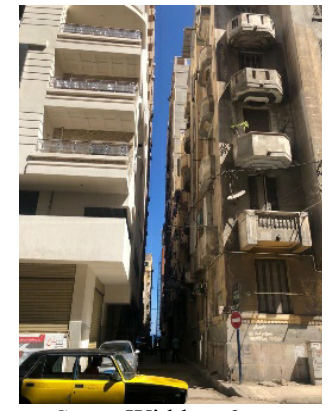

Street Width $=6 \mathrm{~m}$

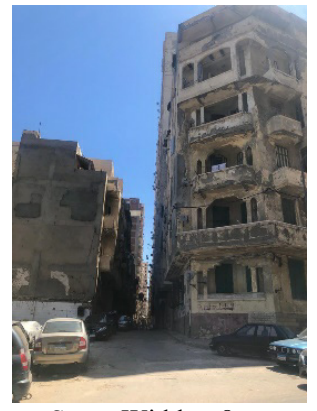

Street Width $=8 \mathrm{~m}$

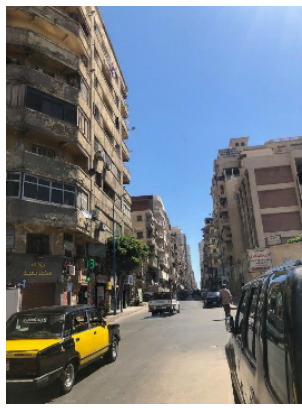

Street Width $=12 \mathrm{~m}$

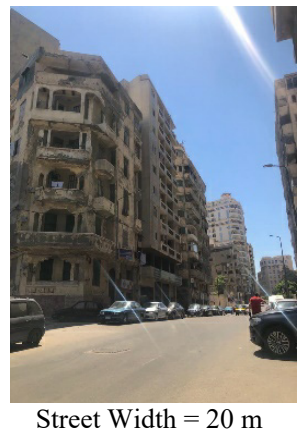

Street Width $=20 \mathrm{~m}$

Figure 4: Current street widths in the study area.

\section{METHODOLOGY}

Natural lighting is a necessary element of human life as unhealthy lighting causes premature aging of the human being and makes him feel tired and weak and is the cause of many diseases. Good urban fabric should achieve the required natural lighting and ventilation within the building, where The height of the building and the depth of the vacuum are the most important factors affecting the intensity of natural light inside the vacuum [12], as well as the placement of openings in the horizontal projection or in the façades [13].

The research was based on the implementation of the current building law of the fourth phase (Law 119 for the year 2008), and the strategic plan of the city of Alexandria in terms of building requirements, lighting and ventilation, to analyse the effect of the law currently used for construction on generating an urban form structure, Then, conducting and analysing the intensity of natural light reaching the interior spaces of the building. The methodology went through two stages:

\subsection{Urban form (the application of the general building requirements)}

Applying the structural heights requirements of Law 119 of 2008 of the strategic plan for the city of Alexandria to the case study to determine the effect of the law on generating an urban fabric, where the law stipulates that the height of the building shall be 1.5 the street width with a maximum height of $42 \mathrm{~m}$. Whereas The intersection buildings heights can be applied from the law stating that: "If the building is located at the intersection of two opposite sides with different widths, the building height is equal to one and a half times the wider road whatever was the depth of the building with a maximum height of 36 meters" (with no height restrictions). 


\subsection{Lighting and ventilation (the application of current building codes)}

Using the Relux program deducing the effect of height barrier from the law and the $8 \%$ opening ratio to calculate the lighting intensity for the different building's floors. Results were extracted and compared with the global lighting rates, starting with ratios of $2 \%$ for the services and multi-use areas, $1 \%$ for the living areas, and $0.5 \%$ of the natural lighting in bedrooms [14]. Using the percentages of openings in the ratios of $10 \%$ and $12 \%$ of the room floor area to conduct the best light intensity suitable for all floors within the building. The results of light intensity were taken in a specific climatic range of the city of Alexandria, selecting a window facing the north with no direct sunlight at 12 noon, on the $21 \mathrm{st}$ of December.

A model of a projection room, balcony room and courtyard room in a residential building which is used to apply the study, is located on Mohamed Shafiq Street with a width of $20 \mathrm{~m}$ as shown in the selected area. The building is $30 \mathrm{~m}$ high, facing a $30 \mathrm{~m}$ high front barrier (Fig. 5).

The selected rooms have an area of $17.3 \mathrm{~m}^{2}$, dimensions of $3.6 \times 4.8 \mathrm{~m}$, internal height of $2.7 \mathrm{~m}$, and an opening space of $1.4 \mathrm{~m}^{2}$ ( $8 \%$ of the floor area of the room). The dimensions of the window are $1.10 \times 1.30 \mathrm{~m}$ and $0.9 \mathrm{~m}$ high from the floor of the room, which is located in the middle of the outer wall in the 3 cases.

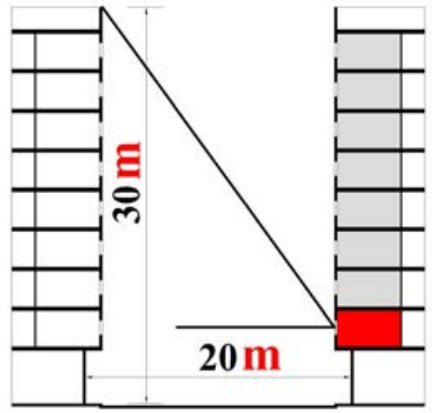

projection room model

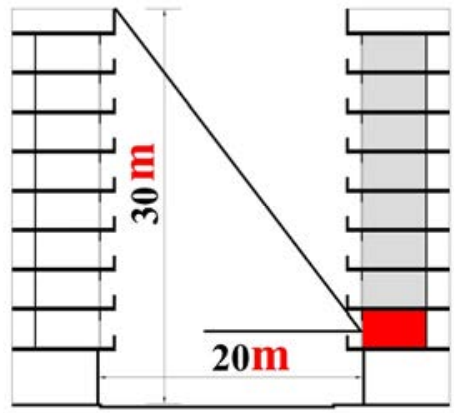

balcony room model

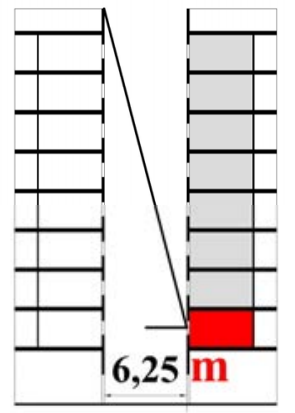

courtyard room model

Figure 5: Relation of the rooms to the road and the residential area of the court (first floor).

\section{RESULT AND DISCUSSION}

\subsection{The application of the general building requirements to the case study}

In Fig. 6 , the building on the street of the $6 \mathrm{~m}$ width rises to $18 \mathrm{~m}$, where it takes the maximum height of the width of the wider front road on Port Said Street. This has resulted in an increase in the number of floors, Similarly, in the other streets, where the street is $8 \mathrm{~m}$ wide, the height of the buildings is $30 \mathrm{~m}$. The street is $12 \mathrm{~m}$ wide and the buildings are $30 \mathrm{~m}$ high. The building takes the maximum height with the width of the front wider road due to the absence of a maximum depth of the building on two different streets as it is allowed to take the height of the wider street. 

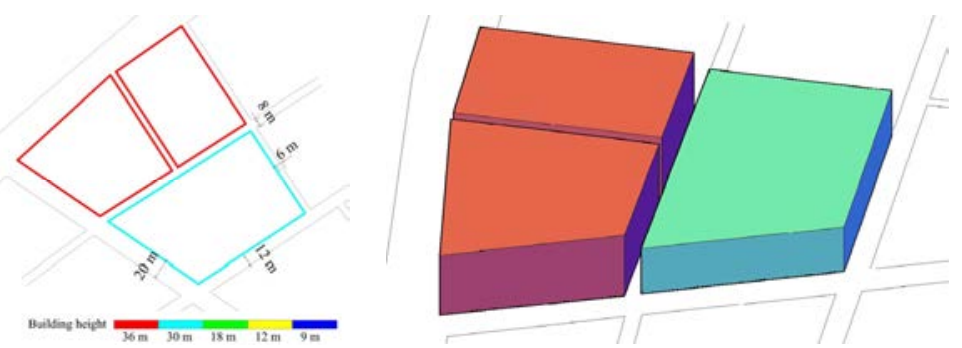

Figure 6: Current law: building heights.

The implementation of the height code in the current law had resulted in a dramatic increase in the number of floors on the same building, resulting in increased population, increased infrastructure burdens and traffic congestions leading to inadequate services. The law does not estimate the volume of traffic resulting from this large number of population and buildings. Therefore, most of the urban roads in Egypt are barely expanding to pedestrian traffic.

The law reflected on the environment of architecture has led to the lack of homogeneity of the architectural character in terms of height, colour contrasts and the chaos of advertisements and signs. It was also found that the law did not deal with the external appearance of buildings or the visual image of urbanization as one of its objectives. The study of the current architecture, which is subject to the Building Law, shows that the owners exploited the loopholes of the building height codes, court areas and projections to achieve the greatest return on their investments regardless of meeting the requirements and needs of the user. The result was a Western architecture with no identity. Social isolation, weak links between the residents, lack of privacy or connection to the surrounding environment appeared as a result of the application of building codes that do not reflect the inherent human relations.

\subsection{The application of the legal lighting and ventilation requirements to the case study}

By using the Relux program, we deduced the intensity of the natural lighting from 1st floor to 9 th floor in the 3 cases. the results of the lighting intensity were obtained in the first floor of each of them as shown in Fig. 7.

By analysing the results, it is found that the floors from 1 to 4 did not achieve the optimum lighting intensity rate in the case of the use of residential buildings, where the intensity of natural light ranges between $(0.42-0.47 \%)$ as shown in Fig. 8 .

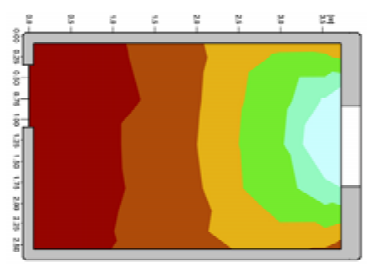

Light intensity in courtyard room

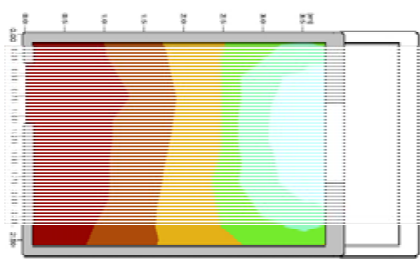

Light intensity in balcony room

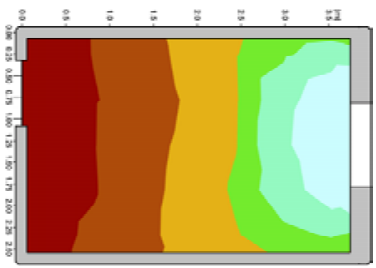

Light intensity in projection room

Illuminance flx)

10

20

30

40

Figure 7: The intensity of the lighting in the rooms in the first floor with a percentage of window area representing $8 \%$ of the floor area. 
Similarly, it was not achieved in floors 1 to 6 in the case of the use of the balconies, where the intensity of natural light ranges between (0.33-0.44\%) as shown in Fig. 8.

Similarly, it was not achieved in floors 1 to 8 in the case of a courtyard room where the intensity of natural light ranges between $(0.24-0.39 \%)$ as shown in Fig. 8.

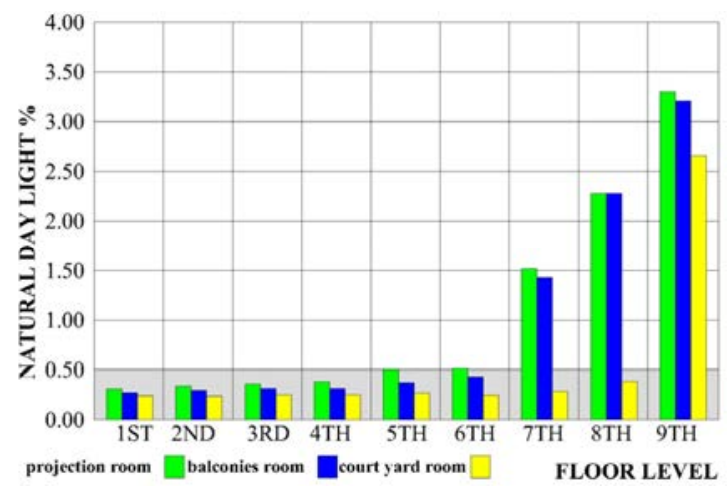

Figure 8: A diagram showing the distribution of lighting intensity in all floors with a percentage of window area representing $8 \%$ of the floor area.

The results of the experiment show the inefficiency of the ratio of the height of the road width 1.5 with the ratio of openings defined in the law by $8 \%$ of the room area for the natural lighting and ventilation of the lower floors. When measuring the intensity of the lighting in the different floors and according to global natural lighting rates for bedrooms, it was found that they did not reach the required amount of $0.5 \%$ of the natural light of the lower floors. Therefore, the experiment was repeated on other ratios in order to reach the required intensity of the entire building.

In the case of using a window opening percentage of $10 \%$ of the room floor area, the opening in the residential projection reached to the required rate of light intensity needed for the residential room as shown in Fig. 9. If the window ratio is $12 \%$ of the room floor area, the room light intensity is in the case of a balcony on the road and in the case of the courtyard room reached to the rate of the natural light required by a residential room as shown in the diagram (Fig. 10).

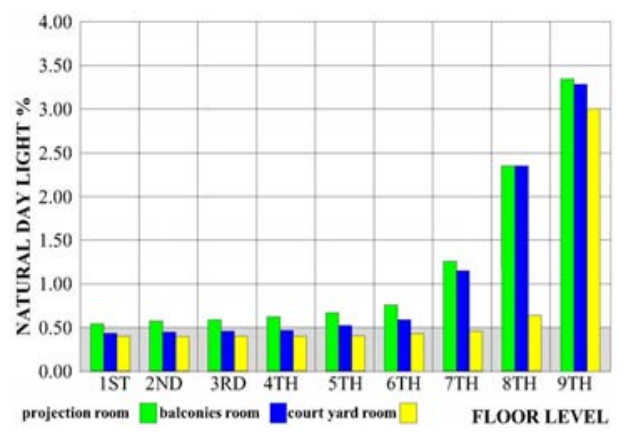

Figure 9: A diagram showing the distribution of light intensity with a window area of $10 \%$ of the floor area. 


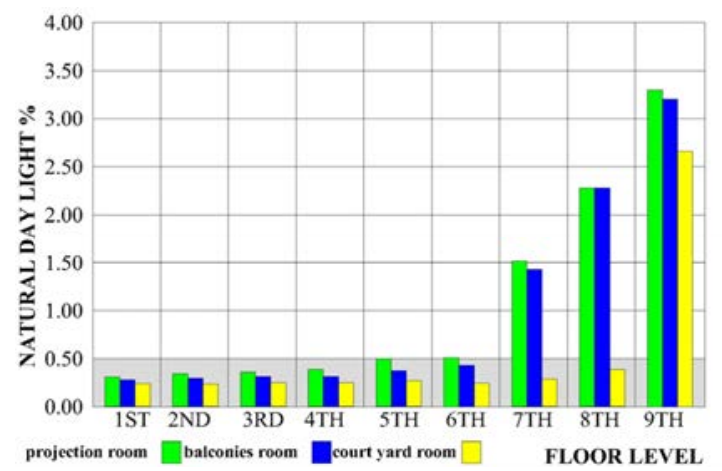

Figure 10: A diagram showing the distribution of light intensity with a percentage of the area of the window equal to $12 \%$ of the floor area.

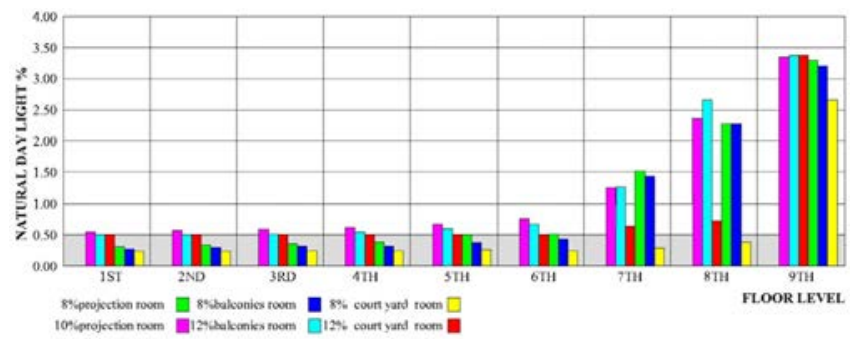

Figure 11: The intensity of natural lighting in the different floors (projection, balcony, and courtyard) in the three ratios of $8 \%, 10 \%, 12 \%$.

Finally, the law did not observe the necessity of the sun light reaching all the floors of the building. The application of the building height code, as one and half the width of the road with an opening area of $8 \%$ of the front space, shows that the lower half of the opposite building is in the shade with no access to the sunlight during the winter. It turned out that it is possible for the sun to access the lower floors of buildings in the winter provided that the height of the corresponding building does not exceed three quarters, such as the width of the road, i.e. half the height allowed by law or the percentage of openings, to be $10 \%$ of the floor area in the case of an opposite residential projections, and $12 \%$ in case of balconies and $12 \%$ if the case of courtyard openings (Fig. 11).

\section{CONCLUSION AND RECOMMENDATIONS}

By reviewing the provisions of the laws and regulations issued in respect of the size and height of buildings, the requirements of natural lighting and the impact of those requirements on the resulting architecture, it is found that the foundations and rules that have been put into the executive regulations of different building laws in Egypt since the first law to regulate the buildings in 1940 until now to control the size of buildings, their height and the size of openings have not changed or developed over forty years, despite their inefficiency.

Finally, the impact of the current legislation organized for the urban environment of the contemporary Egyptian architecture can be summarized as follows. 
By studying the state of contemporary architecture in the city, it is clear that the architecture lacks identity and character and does not meet the requirements and needs of the residents. Most importantly, there is no privacy due to the high rise of buildings. This architecture is not compatible with climatic factors in addition to the graffiti, which is noticed in the formation of buildings façades, which led to the loss of the general character of the city's identity.

By studying the law, it is found that there is nothing about outer open spaces that provide the residents with air and sun except through the area of court, which is optional, as the law does not oblige in any of its items to leave any proportion of the land in favour of spaces. This leads to the fact that the shape of the urban environment after the completion of the constructions can be blocks of bricks and concrete interspersed with roads, which are deep cracks in the urban block with a ratio of width equal to 1:1.5, up to 1:4 in residential areas of room, and 1:14 in service areas of court. These spaces - roads, service areas of court - are the only outlet responsible for providing lighting, ventilation and sun for internal spaces.

Therefore, the following recommendations are made:

- The need to review and amend building codes periodically at close intervals of not more than five years, and whenever necessary.

- Modification of the height codes for the buildings located on two different roads width, through the strategic plans for each city by adding a height constraint up to a specified distance, as follows:

- If the building is located at the intersection of two roads whose width is different, the height of the façade overlooking the smaller road shall rise to the maximum allowable height for the wider road, this height Within a maximum depth in the smaller road equal to the width of the wider road and it shall not exceed $25 \mathrm{~m}$, for example, as stated in phase two with this figure under study to determine the best future value (Fig. 12).

- The ratio of the window area from floor area of space should increase with increasing the front barrier height facing the window up to $10 \%$ of floor area for projection and $12 \%$ for balconies with $56^{\circ}$ angle of elevation in the case of the courtyard room (Fig. 13).

- It is recommended to propose alternatives to the height code of 1.5 of the road with as alternatives to the height of the building, such as following the law of volumes or the law of rebounds, where the structural mass is reduced in order to achieve the desired height for the owner of the building and thus create spaces that allow the passage of air and natural light to the residential units with the same structural size that does not result into an increase in population.

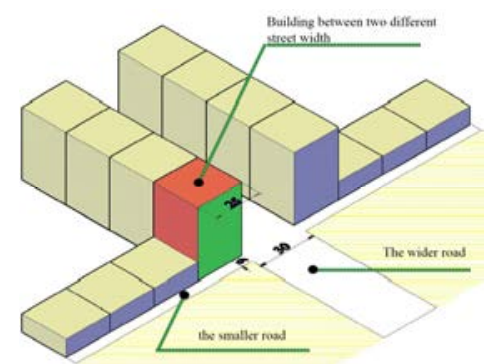

Figure 12: The optimum height for building, located between two different width of road. 


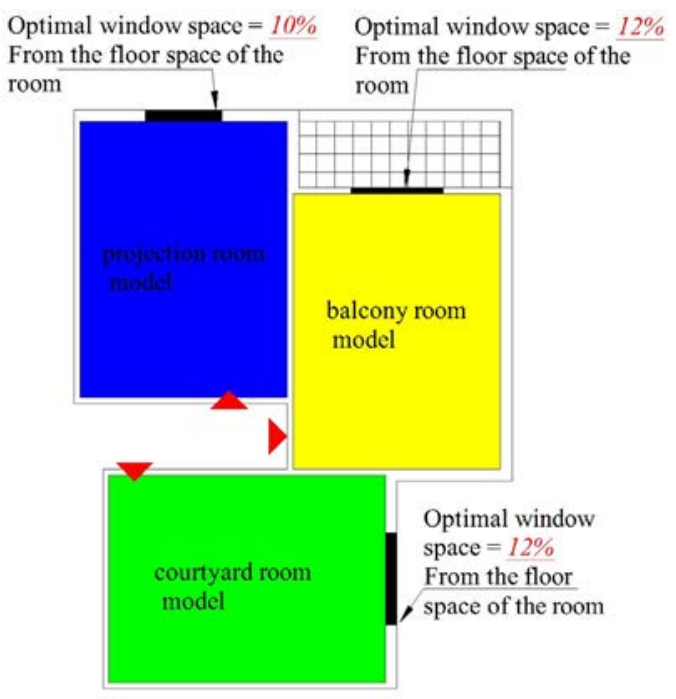

Figure 13: The optimal ratio of window space, for three types of rooms.

\section{REFERENCES}

[1] Soliman, M., Elzamle, H.A. \& Eldin, I.S., The requirements of the regions and their impact on improving the characteristics of the urban environment. Magazine of the Egyptian Society of Engineers, 1(1), pp. 1-3, 2002.

[2] Abd el saboor, M., Planning and organizing construction work legislatively and engineering. Planning and Organizing Construction Work Legislatively and Engineering, eds M. Ibrahim \& M. Taha, Egypt: 2001, pp. 10-13.

www.cpas-egypt.com/pdf/Manar\%20Hosny/MS.c/004.pdf. Accessed on: 2 Jul. 2019.

[3] Daboor, A., Building code gaps and their impact on the urban environment. Academic Research Community, 1(1), pp. 3-7, 2018.

[4] Law 51 of 1940, Egyptian Facts, Issue 79-20 June 1940 - Article 4 Paragraph 2. www.laweg.net. Accessed on: 2 Jul. 2019.

[5] Law 656 of 1954, Egyptian Facts, Issue 98 Bis - December 9, 1954 - Article 15. www.laweg.net. Accessed on: 2 Jul. 2019.

[6] Decision of the Minister of Housing and Utilities 169 of 1962, Official Gazette, Issue 31-4 - February 1962 - Article 6. www.laweg.net. Accessed on: 2 Jul. 2019.

[7] Decision of the Minister of Housing and Construction 237 of 1976 to implement Law 106 of 1976, Egyptian Facts, May 5, 1977 - Article 36. www.laweg.net. Accessed on: 12 Jul. 2019.

[8] Decision of the Minister of Housing and Utilities 268 of 1996 to implement Law 106 of 1976, Egyptian Facts, Issue 170 Followers (b) - 1/8/1977-M20. www.laweg.net. Accessed on: 5 Jul. 2019.

[9] Law 119 of 2008, Official Gazette, Issue 19 bis (a) - May 11, 2008. www.laweg.net. Accessed on: 2 Jul. 2019.

[10] Alexandria Governor's Decision 425 for 2019 to implement Law 119 for 2008 in accordance with the General Strategic Plan for Alexandria 2019. www.laweg.net. Accessed on: 2 Jul. 2019. 
[11] El Wazer, M., Towards a proposed methodology to reduce the urban expansion of Egyptian cities after the January 25 revolution. Journal of Engineering Sciences, 41(6), pp. 7-19, 2013.

[12] Egan, M.D., Concepts in Architectural Lighting, McGraw-Hill, 1983.

[13] Royle, K. \& Terry, C., Hawaiian Design: Strategies for Energy Efficient Architecture, DIANE Publishing, 1990.

[14] Wagih, Y. Architecture and Energy Guide, Egypt: The energy planning device; 1998/07/01.

www.researchgate.net/publication/276144664_dlyl_almart_waltaqt_Architecture_an d_Energy_Guide. Accessed on: 3 Jul. 2019. 